University of Nebraska - Lincoln

DigitalCommons@University of Nebraska - Lincoln

Food and Drug Administration Papers

U.S. Department of Health and Human Services

2019

Youth perception of harm and addictiveness of tobacco products:

Findings from the Population Assessment of Tobacco and Health Study (Wave 1)

\author{
David R. Strong \\ Moores Cancer Center University of California \& University of California, San Diego, dstrong@ucsd.edu \\ Karen Messer \\ Moores Cancer Center University of California \& University of California, San Diego \\ Martha White \\ Moores Cancer Center University of California \& University of California, San Diego \\ Yuyan Shi \\ University of California, San Diego, \\ Madison Noble \\ Moores Cancer Center University of California \& University of California, San Diego \\ Follow this and additional works at: https://digitalcommons.unl.edu/usfda \\ See rext paf the Piertetics and Clipjcal Nutrition Commons, Health and Medical Administration Commons, \\ Health Services Administration Commons, Pharmaceutical Preparations Commons, and the Pharmacy \\ Administration, Policy and Regulation Commons
}

Strong, David R.; Messer, Karen; White, Martha; Shi, Yuyan; Noble, Madison; Portnoy, David B.; Persoskie, Alexander; Kaufman, Annette R.; Choi, Kelvin; Carusi, Charles; Bansal-Travers, Maansi; Hyland, Andrew; and Pierce, John, "Youth perception of harm and addictiveness of tobacco products: Findings from the Population Assessment of Tobacco and Health Study (Wave 1)" (2019). Food and Drug Administration Papers. 54.

https://digitalcommons.unl.edu/usfda/54

This Article is brought to you for free and open access by the U.S. Department of Health and Human Services at DigitalCommons@University of Nebraska - Lincoln. It has been accepted for inclusion in Food and Drug Administration Papers by an authorized administrator of DigitalCommons@University of Nebraska - Lincoln. 


\section{Authors}

David R. Strong, Karen Messer, Martha White, Yuyan Shi, Madison Noble, David B. Portnoy, Alexander

Persoskie, Annette R. Kaufman, Kelvin Choi, Charles Carusi, Maansi Bansal-Travers, Andrew Hyland, and John Pierce 


\title{
Youth perception of harm and addictiveness of tobacco products: Findings from the Population Assessment of Tobacco and Health Study (Wave 1)
}

\author{
David R. Strong ${ }^{\mathrm{a}, \mathrm{b}, *}$, Karen Messer ${ }^{\mathrm{a}, \mathrm{b}}$, Martha White ${ }^{\mathrm{a}, \mathrm{b}}$, Yuyan Shi ${ }^{\mathrm{b}}$, Madison Noble ${ }^{\mathrm{a}, \mathrm{b}}$, \\ David B. Portnoy ${ }^{\mathrm{c}}$, Alexander Persoskie ${ }^{\mathrm{c}}$, Annette R. Kaufman ${ }^{\mathrm{d}}$, Kelvin Choi ${ }^{\mathrm{e}}$, Charles Carusi ${ }^{\mathrm{f}}$, \\ Maansi Bansal-Travers ${ }^{g}$, Andrew Hyland ${ }^{g}$, John Pierce ${ }^{\mathrm{a}, \mathrm{b}}$ \\ ${ }^{a}$ Cancer Prevention \& Control Program, Moores Cancer Center University of California, San Diego, La Jolla, CA, USA \\ ${ }^{\mathrm{b}}$ Department of Family Medicine and Public Health, University of California, San Diego, La Jolla, CA, USA \\ ${ }^{\mathrm{c}}$ Center for Tobacco Products, US Food and Drug Administration, Silver Spring, MD, USA \\ ${ }^{\mathrm{d}}$ Tobacco Control Research Branch, Behavioral Research Program, Division of Cancer Control and Population Sciences, National Cancer Institute, National Institutes of \\ Health, Rockville, MD, USA \\ ${ }^{\mathrm{e}}$ Division of Intramural Research, National Institutes on Minority Health and Health Disparities, Bethesda, MD, USA \\ ${ }^{\mathrm{f}}$ Westat, Rockville, MD, USA \\ ${ }^{g}$ Roswell Park Cancer Institute, Department of Health Behavior, Buffalo, NY, USA
}

\section{H I G H L I G H T S}

- This study assessed youth harm and addictiveness perceptions of six tobacco products.

- Smokeless tobacco, pipe, hookah and e-cigarettes were perceived as less harmful than cigarettes.

- Understanding youth tobacco perceptions remains a focus of prevention efforts.

\section{A R T I C L E I N F O}

\section{Keywords:}

Tobacco harm perceptions

Tobacco addiction perception

Youth tobacco prevention

\begin{abstract}
A B S T R A C T
Purpose: We provide a US national assessment of youth perceptions of the harm and addictiveness of six separate tobacco products, identifying a continuum of perceived harm associated with a range of products in relation to patterns of current use, former use, and susceptibility to use tobacco products.

Methods: We evaluated youth respondents $(N=13,651)$ ages 12-17 from Wave 1 (2013-2014) of the Population Assessment of Tobacco and Health (PATH) Study. Analyses (2015-2016) focused on refining measures of perceived harm for each product and delineating youth characteristics (demographic, tobacco use status) associated with beliefs about the harmfulness and addictiveness of tobacco products.

Results: Cigars, hookah and e-cigarettes were each perceived as having significantly lower harm (p's < 0.05) than smokeless products, with the lowest ratings of harmfulness and addictiveness observed for hookah and ecigarettes (p's < 0.001). Incrementally lower levels of harm and addictiveness perceptions were observed among youth at increasing risk for tobacco use (p's $<0.05$ ).

Conclusions: Among U.S. youth, lower perceptions of harm and addictiveness of tobacco products were associated with susceptibility to use tobacco and patterns of tobacco product use. Future longitudinal assessments from the PATH Study can provide key information on youth development of perceptions of harm and addictiveness and influences on patterns of tobacco use.
\end{abstract}

\section{Introduction}

Adolescents' perceptions of harm and addictiveness of tobacco products may influence their susceptibility to try a specific tobacco product, as well as develop future tobacco use behaviors (Pepper, Ribisl, \& Brewer, 2016; Song, Morrell, Cornell, et al., 2009). Early tobacco use among youth has implications for the development of addiction (U.S. Department of Health and Human Services, 2014), long-

\footnotetext{
* Corresponding author at: Department of Family Medicine and Public Health, University of California, San Diego, 9500 Gilman Drive, MC 0631, La Jolla, CA 92093-0631, United States.

E-mail address: dstrong@ucsd.edu (D.R. Strong).
} 
term exposure to toxicants, and associated health consequences (Hatsukami, Biener, Leischow, et al., 2012). Tobacco companies have employed marketing strategies, such as product design and media advertising, to appeal to target audiences, including young adults, and communicate the impression of their product as less harmful (U.S. Department of Health and Human Services, 2012; Wakefield, Morley, Horan, et al., 2002) While public health professionals have worked to counteract these efforts (Campaign for Tobacco-Free Kids, n.d.; Farrelly, Duke, Nonnemaker, et al., 2017; U.S. Department of Health and Human Services, 2012), there has been an emergence of noncombustible products and new advertising campaigns that could influence youth's perceptions of harm and addictiveness of these products (Grana, Benowitz, \& Glantz, 2014).

Lower perceptions of harm have been previously associated with higher rates of use of many different tobacco products, including a) cigarettes (Halpern-Felsher, Biehl, Kropp, et al., 2004; Song et al., 2009), b) e-cigarettes (Pearson, Richardson, Niaura, et al., 2012), c) snus (Choi, Fabian, Mottey, et al., 2012), and d) hookah (Creamer, Loukas, Li, et al., 2016; Maziak, Eissenberg, \& Ward, 2005). Recent school-based surveys (Chaffee, Gansky, Halpern-Felsher, et al., 2015; Cooper, Harrell, Pérez, et al., 2016; Roditis, Delucchi, Cash, et al., 2016) have assessed youth harm perceptions of tobacco products by asking respondents about the dangers of using a product given their age (Cooper et al., 2016), or asking about the social and physical harms of using a product daily (Chaffee et al., 2015; Roditis et al., 2016). These studies suggest that youth perceive products on a continuum of risk, with cigarettes, cigars and smokeless products ranked higher than hookah and e-cigarettes (Roditis et al., 2016). Importantly, rankings of harm perceptions and addictiveness of tobacco products differ significantly for current users and non-users of tobacco (Chaffee et al., 2015; Cooper et al., 2016). Rankings of harm and addictiveness may also depend upon patterns of product use (e.g., concurrent use of cigarettes), particularly when rankings reflect comparative perceptions of addictiveness for non-cigarette relative to cigarette products (Amrock, Lee, \& Weitzman, 2016; Halpern-Felsher et al., 2004). For example, cigarette smokers were less likely than non-cigarette smokers to endorse e-cigarettes as less harmful than cigarettes but were not less likely than non-cigarette smokers to endorsed e-cigarettes as less addictive than cigarettes (Amrock et al., 2016). Recent examination of youth (Persoskie, O'Brien, Nguyen, et al., 2017) suggests that population surveillance assessing harm and addictiveness perceptions of specific tobacco products remains important in identifying groups susceptible to using tobacco.

The primary aim of this paper was to describe youth perceptions of harm and addictiveness of tobacco products across age, gender, and racial/ethnic groups and to understand patterns among non-users and users of tobacco, using data from the U.S. nationally representative Population Assessment of Tobacco and Health (PATH) Study. We also examined whether perceptions of harm from tobacco products varied among non-users classified by their increasing susceptibility to experimentation. We hypothesized that, compared to youth committed to not using a particular tobacco product, youth who were susceptible to using it, or who experimented with it, would perceive lower levels of harm and addictiveness of the product (including cigarettes, e-cigarettes, cigars, hookah, pipes, smokeless, and multiple tobacco products). Finally, we report how patterns of combustible, non-combustible, and poly-tobacco product use relate to perceptions of one's own and other products.

\section{Methods}

\subsection{Data}

The National Institutes of Health, through the National Institute on Drug Abuse, is partnering with the Food and Drug Administration's Center for Tobacco Products to conduct the PATH Study under a contract with Westat. The PATH Study is an ongoing, nationally-representative, longitudinal cohort study of adults and youth in the US. The PATH Study used audio-computer assisted self-interviews (ACASI) available in English and Spanish to collect self-report information on tobacco-use patterns and associated health behaviors. Wave 1 data collection was conducted from September 12, 2013 to December 14, 2014. This analysis draws from the 13,651 Youth Interviews and includes youth (12-17 years) who had heard of each product and responded to the harm perception and addictiveness questions $(N=13,620)$. The PATH Study recruitment employed a stratified address-based, area-probability sampling, at Wave 1 that oversampled adult tobacco users, young adults (18 to 24 years), and African American adults. An in-person screener was used at Wave 1 to select youths and adults. Population and replicate weights were created that adjusted for the complex study design characteristics (e.g. oversampling at Wave 1) and nonresponse at Wave 1 . Combined with the use of a probability sample, the weights allow analyses of the PATH Study data to compute estimates that are robust and representative of the noninstitutionalized, civilian US population ages 12 and older. At Wave 1, the weighted response rate for the household screener was $54.0 \%$. Among households that were screened, the overall weighted response rate was $78.4 \%$ for the Youth Interview. Further details regarding the PATH Study design and methods including the location of the current study questions within the interview are published by Hyland and colleagues (Hyland, Ambrose, Conway, et al., 2017) and in the User Guide to the PATH Study restricted use files, available at http://www. icpsr.umich.edu/icpsrweb/NAHDAP/series/006061. The study was conducted by Westat and approved by Westat's institutional review board.

\subsection{Study measures}

Assessment domains for the current paper included perceptions of harm from each tobacco product, perceptions of the addictiveness of each tobacco product, susceptibility to use tobacco products, patterns of tobacco product use, and demographic characteristics. We created two primary independent indices to reflect a) levels of risk for tobacco use and b) patterns of tobacco use among users of tobacco products.

\subsubsection{Tobacco products}

Respondents were presented with images of non-cigarette products and asked if they had heard of or used each of the following tobacco products: cigarettes, e-cigarettes, cigars (including traditional cigars, cigarillo, and filtered cigars), pipes, hookah, smokeless tobacco, dissolvable products, bidis, and kreteks. Use of dissolvable products, bidis, and kreteks were not included in this report due to low frequencies of youth who had heard of or used these products.

\subsubsection{Tobacco harm perceptions}

Harm perceptions of cigarettes were assessed with a single item reflecting the absolute harm from using each product, which we refer to as the global harm perception item: "How much do you think people harm themselves when they [USE PRODUCT]?" (response options: '1 = No harm', ' 2 = A little harm', $3=$ Some harm', ' $4=$ A lot of harm'; collapsed to: ' $1=$ No harm or little harm', ' $2=$ Some harm', ' $3=$ A lot of harm'). Harm perceptions for cigars, e-cigarettes, hookah, pipe, and smokeless tobacco were assessed using this same item plus two others assessing the perceived exposure needed to produce harm ("How long do you think someone has to [USE PRODUCT] before it harms their health?"; response options: ' $1=1$ year or less than 1 year', ' $2=5$ or more years', ' $3=$ It will never harm their health') and another item assessing perceived harm relative to cigarettes. ("Is [USING PRODUCT] less harmful, about the same, or more harmful than smoking cigarettes?"; response options: ' 1 = Less harmful', ' $2=$ About the same', ' 3 = More harmful'). All "refused", "don't know," and missing responses 
were treated as missing in analyses. ${ }^{1}$ Given multiple cigar types, we examined each respondent's pattern of responses across questions that inquired about 'traditional', 'cigarillo', and 'filtered' cigars. If respondents had heard of 'cigars' but not the specific type of cigar, they responded to questions about 'traditional, cigarillo or filtered cigars'. In this case, we created a single value for each of the three harm perception questions using the highest rating for any cigar product question.

For cigars, e-cigarettes, hookah, pipe, and smokeless tobacco, we evaluated the appropriateness of combining the three harm perception items into a single composite index for each product type. We examined item inter-correlations to test for internal consistency, and we examined item option associations with summed totals and non-parametric item response curves to test for monotone increasing probability of higher options with higher summed scores (Ramsay, 1991) and to quantify the degree to which increasing item scores were related to increasing summed scores using scalability coefficients for sets of items addressing each product (Sijtsma, 2009). Scalability coefficients can be interpreted as the degree to which subjects can be ordered by mean item responses and thus measure the same construct (Sijtsma \& Meijer, 2007; van Abswoude, van der Ark, \& Sijtsma, 2004). Scalability coefficients range from 0 (i.e., no ordered relationship among item responses and summed levels of harm perceptions) to 1 (i.e., perfect ordering of item responses for people and summed levels of harm perceptions). Scalability coefficients were considered weak if $<0.40$, moderate if between 0.41 and 0.50 , and strong if $>0.50$ (Sijtsma \& Molenaar, 1987).

Only the items for pipes failed to provide evidence for at least moderate scalability $(h=0.32)$; for the other products, there was support for scalability and evidence of reliable measurement provided by internal consistency reliability coefficients (e-cigarettes: $\mathrm{h}=0.62$; alpha $=0.72 ;$ cigars: $\mathrm{h}=0.46 ;$ alpha $=0.57$; hookah: $\mathrm{h}=0.46$; alpha $=0.59$; smokeless tobacco: $h=0.46$; alpha $=0.57$ ). Also, internal consistency estimates for the latter products suggested an acceptable tradeoff given the benefit of multi-item criterion measures, lack of reliability estimates if we had relied upon single items, and an estimated range of potential attenuation of relationships (square root of internal consistency estimate) from a maximum of (1.0 to $0.75-0.85$ [39]t). Thus, harm perceptions for pipes and cigarettes were represented by the single, global item (see above), scaled to mirror the other product indices, whereas harm perceptions for cigars, e-cigarettes, hookah, and smokeless products were represented by the three item index.

\subsubsection{Tobacco addiction perceptions}

We assessed perceptions of the addictiveness of each product using the following question: "How likely is someone to become addicted to [PRODUCT]?" Response options were ' 1 = Very unlikely', ' 2 = Somewhat unlikely', ' $3=$ Neither likely nor unlikely', ' 4 = Somewhat likely', and ' $5=$ Very likely'. All "refused”, "don't know," and missing responses were treated as missing in analyses. ${ }^{2}$

\subsubsection{Tobacco use}

Youth who reported that they had heard of a particular product were asked, "Have you ever tried [PRODUCT]?" (Yes/No). Youth who had ever tried the product were further asked, "When was the last time you [USED PRODUCT]...?" Current users were defined as those reporting use during the past 30 days, and ever/lifetime users were defined as those reporting no use during the past 30 days. Youth who had not ever tried a product were classified as never users of that particular product.

\footnotetext{
${ }^{1}$ Reports of "don't know" ranged from $0.9 \%-2.5 \%$ for the first item, $1.7 \%-5.1 \%$ for the second item, and $4.8 \%-8.4 \%$ for the third item.

${ }^{2}$ Reports of "don't know" ranged from $1.5 \%-5.7 \%$.
}

\subsubsection{Susceptibility index}

For youth who reported never using the corresponding tobacco product, we used a validated susceptibility index (Strong, Hartman, Nodora, et al., 2015) which included the following questions: 'Have you ever been curious about [USING PRODUCT]?'; 'Do you think you will [USE PRODUCT] in the next year?'; 'If one of your best friends were to offer you a [PRODUCT], would you [USE] it?' All never smokers received these questions about cigarettes. For e-cigarettes, cigars, pipes, hookah, and smokeless/snus, participants received these questions about each product if they were a never user of the product and had previously heard of the product. Each question had a 4-level response that ranged from "not at all curious" to "very curious," or from "definitely not" to "definitely yes." Youth who responded with "not at all curious' or 'definitely not' to all three questions were classified as committed never users of that product, while all others were classified as susceptible (Strong et al., 2015). Respondents who "refused" or reported "don't know" were classified as missing.

\subsubsection{Levels of risk for tobacco product use}

For each product, levels of risk were assigned using mutually exclusive groupings of the Susceptibility Index and reports of tobacco use. We classified 'committed never user' at the lowest risk, followed by youth classified as 'susceptible', youth classified as 'ever/lifetime users', and youth classified as having 'used in the past 30 days'.

\subsubsection{Index of tobacco use groups}

Youth who reported no lifetime use of any tobacco products were classified as 'non-users.' Other youth were classified by their lifetime tobacco use/experimentation as 'cigarette only', 'non-cigarette combustible products only' (i.e., only cigar, pipe, hookah, or multiple noncigarette combustible product use), 'e-cigarette only', 'other non-combustible products only' (i.e., only smokeless, snus, or multiple noncombustible product use), or 'poly-tobacco cigarette users' (i.e., both cigarette and non-cigarette products).

\subsubsection{Demographics}

We categorized respondents into age groups of $12-13,14-15$, and 16-17, consistent with other national surveys. Questions assessing gender and race/ethnicity were administered. Missing data on age, gender, race, and Hispanic ethnicity were imputed as described in the PATH Restricted Use File User Guide (United States Department of Health and Human Services, n.d.).

\subsection{Statistical analysis overview}

All estimates are weighted for the PATH study's complex sample design using replicate weights and the Balanced Repeated Replication $(B R R)$ method with Fay adjustment (e.g. Fay $=0.3$ ) computed with the "survey" package (Lumley, 2015) and R statistical software (Team, 2016). Individual hypotheses were tested using separate multivariable regression models assessing harm perceptions and addictiveness perceptions. Models incorporated a standard set of demographic covariates (age, gender, race/ethnicity).

\section{Results}

\subsection{Sample characteristics}

Analyses were limited to youth who had heard of each product and responded to questions about harm perceptions, addictiveness, product use, and susceptibility. Youth who had heard of each product were classified into the following user groups and described using observed sample sizes and weighted percentages: never having tried tobacco products $(n=10,751,80.0 \%)$, cigarette only users $(n=461,3.3 \%)$, non-cigarette combustible product only users (cigar, pipe, or hookah; 
Table 1

Demographic associations with perceived harmfulness and addictiveness of tobacco products.

\begin{tabular}{|c|c|c|c|c|c|c|c|c|c|c|c|c|}
\hline & \multicolumn{4}{|c|}{ Cigarette $^{\mathrm{a}}$} & \multicolumn{4}{|c|}{ E-Cigarette } & \multicolumn{4}{|l|}{ Cigar } \\
\hline & $\mathrm{n}$ & mean & se & $\mathrm{p}$ & $\mathrm{n}$ & mean & se & $\mathrm{p}$ & $\mathrm{n}$ & mean & se & $\mathrm{p}$ \\
\hline Harm perception & 13,620 & 2.79 & 0.01 & & 10,804 & 1.95 & 0.01 & & 7838 & 2.47 & 0.01 & \\
\hline \multicolumn{13}{|l|}{ Age } \\
\hline $12-13$ & 4669 & 2.83 & 0.01 & \multirow[t]{3}{*}{0.000} & 3352 & 2.01 & 0.01 & \multirow[t]{3}{*}{0.000} & 2024 & 2.53 & 0.01 & \multirow[t]{3}{*}{0.000} \\
\hline $14-15$ & 6845 & 2.78 & 0.01 & & 5670 & 1.92 & 0.01 & & 4272 & 2.46 & 0.01 & \\
\hline $16-17$ & 2106 & 2.75 & 0.01 & & 1782 & 1.93 & 0.01 & & 1542 & 2.44 & 0.01 & \\
\hline \multicolumn{13}{|l|}{ Gender } \\
\hline Male & 6978 & 2.78 & 0.01 & \multirow[t]{2}{*}{0.000} & 5512 & 1.89 & 0.01 & \multirow[t]{2}{*}{0.000} & 3985 & 2.47 & 0.01 & \multirow[t]{2}{*}{0.947} \\
\hline Female & 6642 & 2.81 & 0.01 & & 5292 & 2.01 & 0.01 & & 3853 & 2.47 & 0.01 & \\
\hline \multicolumn{13}{|l|}{ Race/ethnicity } \\
\hline Non-hispanic white & 6607 & 2.80 & 0.01 & \multirow[t]{4}{*}{0.129} & 5414 & 1.96 & 0.01 & \multirow[t]{4}{*}{0.000} & 3964 & 2.48 & 0.01 & \multirow[t]{4}{*}{0.000} \\
\hline Hispanic & 3908 & 2.78 & 0.01 & & 2978 & 1.97 & 0.01 & & 1978 & 2.49 & 0.01 & \\
\hline Black & 1856 & 2.78 & 0.01 & & 1435 & 1.86 & 0.01 & & 1192 & 2.41 & 0.02 & \\
\hline Other non-hispanic & 1249 & 2.81 & 0.01 & & 977 & 1.99 & 0.02 & & 704 & 2.51 & 0.02 & \\
\hline Addictiveness perception & 13,420 & 4.09 & 0.01 & & 11,456 & 3.6 & 0.01 & & 8304 & 3.99 & 0.02 & \\
\hline Age & & & & & & & & & & & & \\
\hline $12-13$ & 4542 & 4.03 & 0.02 & 0.000 & 3631 & 3.75 & 0.02 & 0.000 & 2225 & 4.19 & 0.02 & 0.000 \\
\hline $14-15$ & 6782 & 4.12 & 0.01 & & 5944 & 3.56 & 0.02 & & 4477 & 3.96 & 0.02 & \\
\hline $16-17$ & 2096 & 4.12 & 0.03 & & 1881 & 3.47 & 0.03 & & 1602 & 3.81 & 0.03 & \\
\hline Gender & & & & & & & & & & & & \\
\hline Male & 6877 & 4.05 & 0.01 & 0.000 & 5879 & 3.51 & 0.02 & 0.000 & 4234 & 3.91 & 0.02 & 0.000 \\
\hline Female & 6543 & 4.13 & 0.02 & & 5577 & 3.71 & 0.02 & & 4070 & 4.08 & 0.02 & \\
\hline Race/ethnicity & & & & & & & & & & & & \\
\hline Non-hispanic white & 6500 & 4.20 & 0.01 & 0.000 & 5737 & 3.63 & 0.02 & 0.007 & 4203 & 4.01 & 0.02 & 0.303 \\
\hline Hispanic & 3850 & 3.92 & 0.02 & & 3147 & 3.55 & 0.02 & & 2094 & 3.96 & 0.03 & \\
\hline Black & 1840 & 3.96 & 0.03 & & 1526 & 3.56 & 0.03 & & 1256 & 3.94 & 0.04 & \\
\hline Other non-hispanic & 1230 & 4.06 & 0.04 & & 1046 & 3.66 & 0.04 & & 751 & 4.00 & 0.05 & \\
\hline & Pipe $^{a}$ & & & & Hookal & & & & Smok & & & \\
\hline & $\mathrm{n}$ & mean & se & $\mathrm{p}$ & $\mathrm{n}$ & mean & se & $\mathrm{p}$ & $\mathrm{n}$ & mean & se & $\mathrm{p}$ \\
\hline Harm perception & 11,376 & 2.5 & 0.01 & & 7518 & 2.22 & 0.01 & & 9226 & 2.49 & 0.01 & \\
\hline Age & & & & & & & & & & & & \\
\hline $12-13$ & 3658 & 2.56 & 0.01 & 0.000 & 1671 & 2.35 & 0.01 & 0.000 & 2640 & 2.47 & 0.01 & 0.000 \\
\hline $14-15$ & 5884 & 2.48 & 0.01 & & 4249 & 2.21 & 0.01 & & 4977 & 2.50 & 0.01 & \\
\hline $16-17$ & 1834 & 2.46 & 0.02 & & 1598 & 2.14 & 0.01 & & 1609 & 2.52 & 0.01 & \\
\hline Gender & & & & & & & & & & & & \\
\hline Male & 5794 & 2.48 & 0.01 & 0.000 & 3622 & 2.24 & 0.01 & 0.005 & 4732 & 2.48 & 0.01 & 0.000 \\
\hline Female & 5582 & 2.52 & 0.01 & & 3896 & 2.21 & 0.01 & & 4494 & 2.51 & 0.01 & \\
\hline Race/ethnicity & & & & & & & & & & & & \\
\hline Non-hispanic white & 5897 & 2.49 & 0.01 & 0.014 & 3475 & 2.23 & 0.01 & 0.091 & 5201 & 2.48 & 0.01 & 0.005 \\
\hline Hispanic & 3011 & 2.52 & 0.01 & & 2346 & 2.21 & 0.01 & & 2142 & 2.52 & 0.01 & \\
\hline Black & 1395 & 2.50 & 0.02 & & 972 & 2.21 & 0.02 & & 1002 & 2.50 & 0.02 & \\
\hline Other non-hispanic & 1073 & 2.56 & 0.02 & & 725 & 2.27 & 0.02 & & 881 & 2.54 & 0.02 & \\
\hline Addictiveness perception & 11,020 & 4.07 & 0.01 & & 7888 & 3.72 & 0.02 & & 9695 & 4.33 & 0.01 & \\
\hline Age & & & & & & & & & & & & \\
\hline $12-13$ & 3513 & 4.12 & 0.02 & 0.001 & 1816 & 4.00 & 0.03 & 0.000 & 2902 & 4.34 & 0.02 & 0.502 \\
\hline $14-15$ & 5716 & 4.07 & 0.01 & & 4425 & 3.69 & 0.02 & & 5145 & 4.32 & 0.01 & \\
\hline $16-17$ & 1791 & 4.00 & 0.02 & & 1647 & 3.49 & 0.04 & & 1648 & 4.33 & 0.02 & \\
\hline Gender & & & & & & & & & & & & \\
\hline Male & 5595 & 4.00 & 0.02 & 0.000 & 3839 & 3.67 & 0.02 & 0.002 & 4965 & 4.27 & 0.01 & 0.000 \\
\hline Female & 5425 & 4.15 & 0.02 & & 4049 & 3.76 & 0.02 & & 4730 & 4.39 & 0.01 & \\
\hline Race/ethnicity & & & & & & & & & & & & \\
\hline Non-hispanic white & 5685 & 4.12 & 0.02 & 0.000 & 3641 & 3.70 & 0.02 & 0.521 & 5455 & 4.37 & 0.01 & 0.000 \\
\hline Hispanic & 2941 & 4.03 & 0.02 & & 2457 & 3.71 & 0.03 & & 2251 & 4.23 & 0.02 & \\
\hline Black & 1363 & 3.97 & 0.03 & & 1026 & 3.77 & 0.04 & & 1067 & 4.22 & 0.03 & \\
\hline Other non-hispanic ${ }^{\mathrm{b}}$ & 1031 & 4.04 & 0.03 & & 764 & 3.73 & 0.04 & & 922 & 4.35 & 0.03 & \\
\hline
\end{tabular}

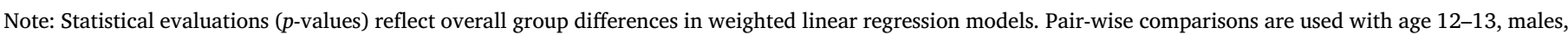
and Non-Hispanic White as reference groups for age, gender, race/ethnicity.

a Indicates use of single-item assessment of harm perceptions.

b Indicates significant pairwise comparisons.

$n=431,3.2 \%)$, e-cigarettes only users $(n=309,2.3 \%)$, other noncombustible product only users (smokeless, snus, or multiple noncombustible products; $n=129,1.0 \%$ ), or poly-tobacco product users (both cigarette and non-cigarette; $n=1377,10.2 \%$ ). Among poly-tobacco users, e-cigarette use was most common (70.7\%).

\subsection{Harm and addictiveness perceptions by age, gender, racial/ethnic group}

Table 1 shows the average perceptions of harm (range 1-3) and addictiveness (range 1-5) for each product within age, gender, and racial ethnic status groups. On average, youth rated products highly on 
the global harm perception item $\left(M_{\text {cigarettes }}=2.79\right.$, se $=0.01$; $M_{\text {pipes }}=2.50$, se $=0.01$ ) and the three-item harm perception index $\left(M_{\text {e-cigarettes }}=1.95, \quad\right.$ se $=0.01 ; \quad M_{\text {cigars }}=2.47, \quad$ se $=0.01$; $M_{\text {hookah }}=2.22$, se $=0.01 ; M_{\text {smokeless tobacco }}=2.49$, se $=0.01$ ). Similar patterns were observed with perceptions of the addictiveness of each product, with cigarettes $(M=4.09$, se $=0.01)$, e-cigarettes $(M=3.60$, se $=0.01)$, cigars $(M=3.99$, se $=0.02)$, pipe $(M=4.07$, se $=0.01)$, hookah $(M=3.72$, se $=0.02)$, and smokeless tobacco $(M=4.33$; $\mathrm{se}=0.01)$ in the range of 'somewhat' to 'very likely' addictive, on average.

Perceived harm and addictiveness of nearly all examined tobacco products differed significantly across age groups (Table 1 ). Compared to younger youth (12-13 year-olds), older youth (14-15 and 16-17 yearolds) perceived all products except for smokeless tobacco as less harmful ( $p$ 's < 0.01), and perceived e-cigarettes, cigars, pipe, and hookah as less addictive (p's $<0.01$ ). In contrast, older youth perceived smokeless tobacco as more harmful than did younger youth $(p<0.001)$, and perceived cigarettes as more addictive than did younger youth. Perceptions of addictiveness from smokeless tobacco were not significantly different across age groups $(p=0.50)$.

Compared to males, females rated all products as more addictive $(p$ 's $<0.01)$ and, with the exception of cigars and hookah, as slightly more harmful ( $p$ 's $<0.01$; Table 1). Differences in perceived harm and addictiveness were also observed across ethnic/racial groups, with the exception of perceived harm of cigarettes and perceived addictiveness of cigars and hookah ( $p$ 's $\leq 0.01$; Table 1$)$.

\subsection{Patterns of harm and addictiveness perceptions across tobacco products}

Survey weighted regression models tested whether harm and addictiveness perceptions differed across products (See Table 1 ). When we compared perceptions of harm from cigars, e-cigarettes, hookah, and smokeless products, we found significant differences in mean ratings across products $(F(3,96)=2930.83, p<0.001) .^{3}$ Follow-up comparisons, found that, when compared to smokeless products, cigars (mean difference $=-0.02$, se $=0.01, p<0.01$ ), hookah (mean difference $=-0.27$, se $=0.01, p<0.01$ ), and e-cigarettes (mean difference $=-0.54$, se $=01, p<0.01$ ) each had significantly lower harm perception ratings.

Perceived addictiveness also differed significantly across products $(F$ $(5,94)=682.48, p<0.001)$. Compared to cigarettes $($ mean $=4.09$, se $=0.01$ ), e-cigarettes (mean difference $=-0.49, \quad$ se $=0.01$, $p<0.01$ ), cigars (mean difference $=-0.10$, se $=0.01, p<0.01$ ), and hookah (mean difference $=-0.37$, se $=0.01, p<0.01$ ) were each rated as less addictive. Smokeless products were rated as more addictive than cigarettes (mean difference $=0.24$, se $=0.01$, $p<0.001$ ), and pipes were rated similarly to cigarettes (mean difference $=-0.02$, se $=0.01, p \geq 0.05$ ).

\subsection{Levels of risk for tobacco product use and product harm/addictiveness perceptions}

When compared to committed never users, youth classified as susceptible to use, ever/lifetime users, and current users demonstrated consistently lower levels of perceived harm across products ( $p$ 's < 0.05; see Table 2). Moreover, for each of the non-cigarette products, susceptible youth and those who had ever used each product had lower perceived addictiveness when compared to committed never users ( $p$ 's $<0.05)$. For cigarettes, youth who had ever tried cigarettes or smoked cigarettes in the past 30 days had lower perceived addictiveness than committed never users $(p<0.05)$, but perceived addictiveness

\footnotetext{
${ }^{3}$ Cigarettes and pipes were excluded from this analysis because they were assessed using the single global harm perception item rather than the three-item index.
}

among susceptible youth was not statistically significant from that among committed never users (see Fig. 1).

\subsection{Perceptions of product harm/addictiveness by type of tobacco user}

Table 2 lists results from multivariable regression models with adjustment for planned covariates comparing tobacco product user groups' perceptions of harm and addictiveness. Youth who were tobacco product users tended to perceive tobacco products as significantly less harmful and less addictive (p's < 0.05) than youth classified as committed never tobacco users, with a few exceptions. For products other than cigarettes and smokeless, this was particularly evident in users' perceptions of the addictiveness of their own products, which they tended to perceive as less addictive relative to never users. Among cigarette smokers (i.e., cigarette only and poly-tobacco users who smoked cigarettes) and smokeless users, perceived addictiveness of their own products remained high and was similar to that of never users: While cigarette smokers' perceived addictiveness of cigarettes differed from that of never users by -0.13 , analogous differences were -0.66 for e-cigarette only users' perceived addictiveness of e-cigarettes and -0.79 and -0.43 for non-cigarette combustible product users' perceived addictiveness of hookah and cigars, respectively.

For e-cigarette products, the lowest perceptions of harm and addictiveness were among e-cigarette only users, poly-tobacco users, and users of other non-combustible products compared to never user groups ( $p$ 's $<0.01)$. Perceived harm and addictiveness of cigar and pipe products were lowest among poly-tobacco users and youth using non-cigarette combustible products. Perceived harm and addictiveness of hookah use were also lower among poly-tobacco users, non-cigarette combustible product users, and e-cigarette only users than other user groups. We observed significantly lower harm perceptions of smokeless tobacco products among other non-combustible product users, but relatively small differences in other user groups when comparing tobacco users to never tobacco users. Ratings of the addictiveness of smokeless products was lowest among poly-tobacco users.

No significant differences emerged in perceptions of harm and addictiveness of hookah when comparing cigarette only and never tobacco users. In addition, no differences emerged in harm perceptions of smokeless products between cigarette only and never tobacco users.

\section{Discussion}

Population estimates of U.S. youth perceptions of harm and addictiveness from tobacco products showed cross-product differences, ageand sex-related associations, and links to tobacco product use behaviors and susceptibility to future use. Higher perceived harm and addictiveness of cigarettes, e-cigarettes, pipe, hookah, and smokeless tobacco products were negatively associated with susceptibility and use of these products.

Our nationally representative results are consistent with previous studies in which youth appear to endorse a gradient of product harm and addictiveness (Ambrose, Rostron, Johnson, et al., 2014), with hookah (Eissenberg, Ward, Smith-Simone, et al., 2008; Maziak, Ward, \& Eissenberg, 2007; Ward, Eissenberg, Gray, et al., 2007) and e-cigarettes (Amrock, Zakhar, Zhou, et al., 2014; Dutra \& Glantz, 2014; Pearson et al., 2012) rated significantly less harmful than cigarettes. We extended these results using a U.S. national sample of youth aged 12-17 years-old and a broadened examination of perceived harm and addictiveness of these products. How these perceptions may be influencing poly-use patterns, such as rising rates of dual use of cigarettes and e-cigarettes (Dutra \& Glantz, 2014), is worth future attention. We observed significant associations between patterns of use with different tobacco products and perceptions of harm and addictiveness. Although poly-tobacco product users tended to rate each product as less harmful and less addictive than did never users, single product users' view of the harm and addictiveness of tobacco depended on whether they had used 
Table 2

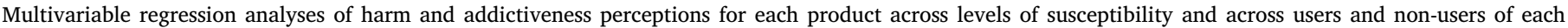
tobacco product.

\begin{tabular}{|c|c|c|c|c|c|c|c|c|c|}
\hline & \multicolumn{3}{|c|}{ Cigarettes $(n=13,620)$} & \multicolumn{3}{|c|}{$E$-Cigarettes $(\mathrm{n}=12,178)$} & \multicolumn{3}{|c|}{ Cigars $(n=11,875)$} \\
\hline & Estimate & Std. Error & $\operatorname{Pr}(>|t|)$ & Estimate & Std. Error & $\operatorname{Pr}(>|t|)$ & Estimate & Std. Error & $\operatorname{Pr}(>|t|)$ \\
\hline \multicolumn{10}{|l|}{ Tobacco product susceptibility and use } \\
\hline \multicolumn{10}{|l|}{ Harm perceptions } \\
\hline Never smoker (reference) & - & - & - & - & - & - & - & - & - \\
\hline Susceptible & -0.14 & 0.01 & 0.000 & -0.34 & 0.01 & 0.000 & -0.22 & 0.01 & 0.000 \\
\hline Ever tried: Not Past 30d & -0.17 & 0.02 & 0.000 & -0.45 & 0.02 & 0.000 & -0.23 & 0.02 & 0.000 \\
\hline Ever tried: Used Past 30d & -0.44 & 0.03 & 0.000 & -0.64 & 0.02 & 0.000 & -0.32 & 0.03 & 0.000 \\
\hline \multicolumn{10}{|l|}{ Addictiveness } \\
\hline Never smoker (reference) & - & - & - & - & - & - & - & - & - \\
\hline Susceptible & -0.01 & 0.03 & 0.783 & -0.36 & 0.02 & 0.000 & -0.40 & 0.03 & 0.000 \\
\hline Ever tried: Not Past 30d & -0.13 & 0.03 & 0.000 & -0.84 & 0.05 & 0.000 & -0.70 & 0.05 & 0.000 \\
\hline Ever tried: Used Past 30d & -0.18 & 0.05 & 0.000 & -1.15 & 0.07 & 0.000 & -0.81 & 0.07 & 0.000 \\
\hline \multicolumn{10}{|l|}{ Tobacco product user group } \\
\hline \multicolumn{10}{|l|}{ Harm perceptions } \\
\hline Never tobacco user (reference) & - & - & - & - & - & - & - & - & - \\
\hline Cigarette only & -0.17 & -4.82 & 0.000 & -0.13 & 0.03 & 0.000 & -0.11 & 0.04 & 0.015 \\
\hline Poly-tobacco user: Cigarette + Other Product(s) & -0.26 & -14.41 & 0.000 & -0.35 & 0.02 & 0.000 & -0.27 & 0.02 & 0.000 \\
\hline E-cigarettes only & -0.09 & -2.82 & 0.006 & -0.42 & 0.03 & 0.000 & -0.16 & 0.06 & 0.008 \\
\hline Other non-combustible & -0.06 & -1.42 & 0.159 & -0.20 & 0.04 & 0.000 & -0.03 & 0.06 & 0.635 \\
\hline Non-cigarette combustible product user & -0.04 & -1.39 & 0.167 & -0.10 & 0.03 & 0.004 & -0.30 & 0.04 & 0.000 \\
\hline \multicolumn{10}{|l|}{ Addictiveness } \\
\hline Never tobacco user (reference) & - & - & - & - & - & - & - & - & - \\
\hline Cigarette only & -0.13 & 0.05 & 0.013 & -0.33 & 0.06 & 0.000 & -0.28 & 0.06 & 0.000 \\
\hline Poly-tobacco user: Cigarette + Other Product(s) & -0.15 & 0.04 & 0.000 & -0.81 & 0.04 & 0.000 & -0.60 & 0.04 & 0.000 \\
\hline E-cigarettes only & -0.04 & 0.07 & 0.598 & -0.66 & 0.07 & 0.000 & -0.30 & 0.10 & 0.002 \\
\hline Other/Multiple non-combustible & -0.02 & 0.11 & 0.834 & -0.26 & 0.11 & 0.028 & 0.20 & 0.08 & 0.016 \\
\hline \multirow[t]{3}{*}{ Non-cigarette combustible product user } & 0.02 & 0.06 & 0.692 & -0.23 & 0.06 & 0.000 & -0.43 & 0.06 & 0.000 \\
\hline & \multicolumn{3}{|c|}{ Pipe $(n=11,613)$} & \multicolumn{3}{|c|}{ Hookah $(n=8362)$} & \multicolumn{3}{|c|}{ Smokeless $(\mathrm{n}=10,123)$} \\
\hline & Estimate & Std. Error & $\operatorname{Pr}(>|t|)$ & Estimate & Std. Error & $\operatorname{Pr}(>|t|)$ & Estimate & Std. Error & $\operatorname{Pr}(>|\mathrm{t}|)$ \\
\hline \multirow{2}{*}{\multicolumn{10}{|c|}{$\begin{array}{l}\text { Tobacco product susceptibility and use } \\
\text { Harm perceptions }\end{array}$}} \\
\hline & \\
\hline Never smoker (reference) & - & - & - & - & - & - & - & - & - \\
\hline Susceptible & -0.35 & 0.02 & 0.000 & -0.33 & 0.01 & 0.000 & -0.23 & 0.02 & 0.000 \\
\hline Ever tried: Not Past 30d & -0.39 & 0.05 & 0.000 & -0.42 & 0.02 & 0.000 & -0.18 & 0.02 & 0.000 \\
\hline Ever tried: Used Past 30d & -0.66 & 0.13 & 0.000 & -0.53 & 0.04 & 0.000 & -0.54 & 0.04 & 0.000 \\
\hline \multicolumn{10}{|l|}{ Addictiveness } \\
\hline Never smoker (reference) & - & - & - & - & - & - & - & - & - \\
\hline Susceptible & -0.36 & 0.03 & 0.000 & -0.62 & 0.03 & 0.000 & -0.32 & 0.03 & 0.000 \\
\hline Ever tried: Not Past 30d & -0.60 & 0.09 & 0.000 & -1.09 & 0.06 & 0.000 & -0.35 & 0.07 & 0.000 \\
\hline Ever Tried: Used Past 30d & -0.95 & 0.22 & 0.000 & -1.32 & 0.09 & 0.000 & -0.47 & 0.09 & 0.000 \\
\hline Tobacco product user group & & & & & & & & & \\
\hline Harm perceptions & & & & & & & & & \\
\hline Never tobacco user (reference) & - & - & - & - & - & - & - & - & - \\
\hline Cigarette only & -0.16 & 0.03 & 0.000 & 0.00 & 0.03 & 0.908 & -0.01 & 0.02 & 0.733 \\
\hline Poly-tobacco user: Cigarette + Other Product(s) & -0.21 & 0.02 & 0.000 & -0.16 & 0.02 & 0.000 & -0.08 & 0.01 & 0.000 \\
\hline E-cigarettes only & -0.19 & 0.04 & 0.000 & -0.18 & 0.04 & 0.000 & 0.00 & 0.03 & 0.863 \\
\hline Other non-combustible & 0.03 & 0.07 & 0.702 & -0.07 & 0.07 & 0.265 & -0.28 & 0.05 & 0.000 \\
\hline Non-cigarette combustible product user & -0.20 & 0.04 & 0.000 & -0.32 & 0.03 & 0.000 & -0.07 & 0.03 & 0.009 \\
\hline Addictiveness & & & & & & & & & \\
\hline Never tobacco user (reference) & - & - & - & - & - & - & - & - & - \\
\hline Cigarette only & -0.21 & 0.04 & 0.000 & -0.12 & 0.07 & 0.103 & -0.12 & 0.06 & 0.028 \\
\hline Poly-tobacco user: Cigarette + Other Product(s) & -0.41 & 0.04 & 0.000 & -0.66 & 0.05 & 0.000 & -0.25 & 0.04 & 0.000 \\
\hline E-cigarettes only & -0.20 & 0.06 & 0.001 & -0.37 & 0.09 & 0.000 & -0.08 & 0.07 & 0.251 \\
\hline Other/multiple non-combustible & 0.06 & 0.09 & 0.477 & 0.00 & 0.15 & 0.987 & -0.21 & 0.12 & 0.072 \\
\hline Non-cigarette combustible product user & -0.25 & 0.06 & 0.000 & -0.79 & 0.07 & 0.000 & -0.16 & 0.06 & 0.006 \\
\hline
\end{tabular}

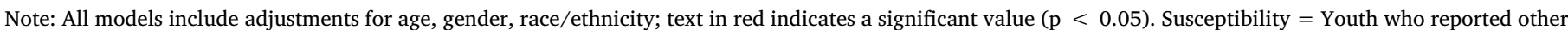

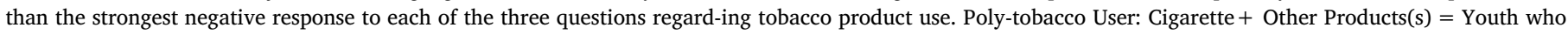

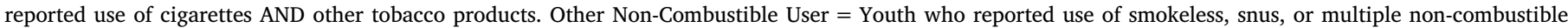

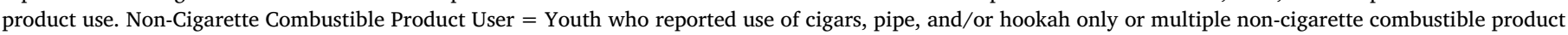
use.

cigarette, non-cigarette combustible, e-cigarette, or non-combustible products. Differences in perceptions of harm and addictiveness by use status may reflect the influence of perceptions on behavior (e.g., high perceived harm and addictiveness may discourage trial), the influence of behavior on perceptions (e.g., trial may stimulate users to reappraise and lower their perceived harm and addictiveness), or both. Interestingly, cigarette only smokers appeared similar to never tobacco users in ratings of the harm and addictiveness of hookah and smokeless 

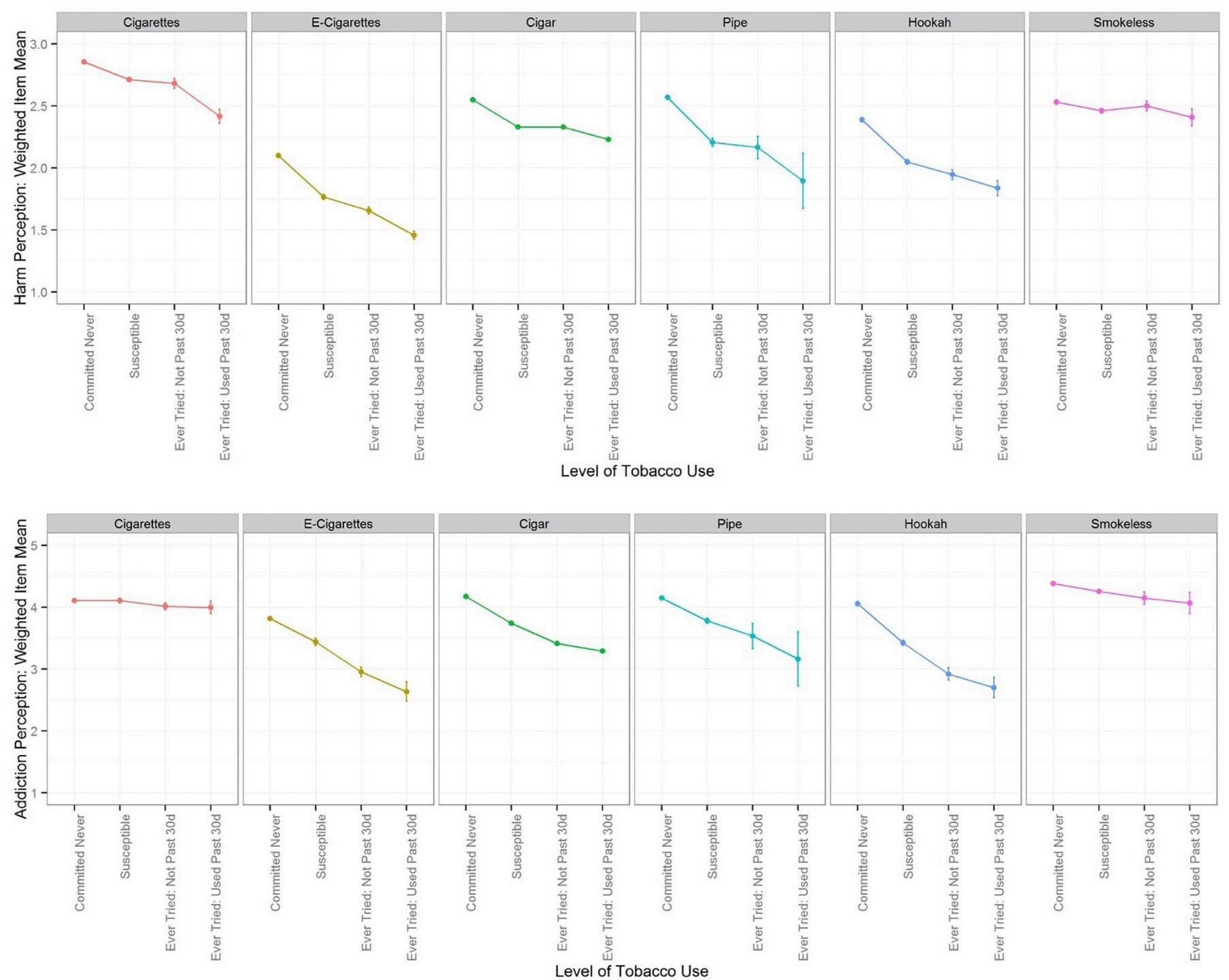

Fig. 1. Perceptions of harm and addictiveness of tobacco products by level of risk for tobacco use.

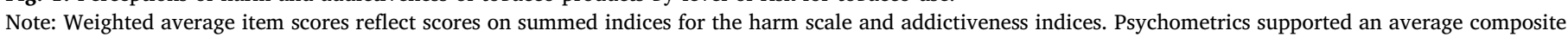
score of harm perceptions for all products except cigarettes and pipe, which used the first question only.

products, whereas hookah and smokeless users rated their products as having lower harm and addictiveness than never tobacco users. These associations suggest the potential product-specific, reciprocal influences between product perceptions and interactions with the product.

Perceptions of harm and addictiveness of products may best be characterized on a continuum, with youth who perceived gradations in levels of harm at higher risk for tobacco use initiation. ${ }^{16}$ In theory, developing curiosity about products may generate reappraisal and lowering of harm perceptions which in turn promotes susceptibility to use. Progressing to experimentation may motivate further re-appraisals and further lowering of harm and addictiveness perceptions. These data were consistent with both the hypothesis that lowering of harm perceptions may influence susceptibility to tobacco use and the hypothesis that experiencing the biologically rewarding effects of tobacco product use may promote lowering of harm perceptions as youth progress beyond experimentation. The concurrent assessment harm and addictiveness perceptions among youth with different levels of risk for tobacco use cannot inform whether perceptions influence risk for use or if youth with greater risk for use also have lower perceptions of harm and addictiveness. Longitudinal evaluation of the development of harm perceptions and addictiveness perceptions may provide better insight into the influence of these cognitions in promoting tobacco use initiation and progression. Our findings highlight the importance of harm perceptions for health communications, public health messaging campaigns, and clinical communications for youth that include non-cigarette products and not a focus on cigarettes alone (Kaufman, Suls, \& Klein, 2016).

This nationally representative U.S. sample provided summary information about perceptions of harm and addictiveness for tobacco products across key sociodemographic groups, product use susceptibility, and current and prior product use status. However, cross-sectional data cannot determine temporal relationships between risk perceptions and initiation or maintenance of tobacco product use. Subsequent waves of the PATH Study may reveal the extent to which low perceived harm and addictiveness of tobacco products predispose U.S. youth to tobacco use, rather than the reverse. Development of multi-item instruments to assess perceptions of harm and addictiveness could increase confidence in the reliability of measurement and advance movement towards a standard for cross-product comparisons (Kaufman, Suls, \& Klein, 2016). 


\section{Conclusions}

Lower perceptions of harm and addictiveness of tobacco products were associated with higher risk for tobacco product use among U.S. youth. A better understanding of longitudinal associations between perceptions and tobacco product features and use patterns among current users, as well as the potential for increased initiation of tobacco use among youth, may inform the assessment of product impact on public health.

\section{Funding Source}

This manuscript is supported with Federal funds from the National Institute on Drug Abuse, National Institutes of Health, and the Center for Tobacco Products, Food and Drug Administration, Department of Health and Human Services, under a contract to Westat (Contract No. HHSN271201100027C). No financial disclosures were reported by the authors of this paper.

\section{Disclaimer}

The views and opinions expressed in this manuscript are those of the authors only and do not necessarily represent the views, official policy or position of the U.S. Department of Health and Human Services or any of its affiliated institutions or agencies.

\section{References}

van Abswoude, A. A. H., van der Ark, L. A., \& Sijtsma, K. (2004). A comparative study of test data dimensionality assessment procedures under nonparametric IRT models. Applied Psychological Measurement, 28, 3-24.

Ambrose, B. K., Rostron, B. L., Johnson, S. E., et al. (2014). Perceptions of the relative harm of cigarettes and e-cigarettes among U.S. youth. American Journal of Preventive Medicine, 47, S53-S60. https://doi.org/10.1016/j.amepre.2014.04.016.

Amrock, S. M., Lee, L., \& Weitzman, M. (2016). Perceptions of e-cigarettes and noncigarette tobacco products among US youth. Pediatrics, 138(5), e20154306. https:// doi.org/10.1542/peds.2015-4306.

Amrock, S. M., Zakhar, J., Zhou, S., et al. (2014). Perception of e-cigarettes' harm and its correlation with use among U.S. adolescents. Nicotine \& Tobacco Research, 17(3), 330-336. https://doi.org/10.1093/ntr/ntu156.

Campaign for Tobacco-Free Kids Campaign for tobacco-free kids. http://www. tobaccofreekids.org/index.php.

Chaffee, B. W., Gansky, S. A., Halpern-Felsher, B., et al. (2015). Conditional risk assessment of adolescents' electronic cigarette perceptions. American Journal of Health Behavior, 39, 421-432. https://doi.org/10.5993/AJHB.39.3.14.

Choi, K., Fabian, L., Mottey, N., et al. (2012). Young adults' favorable perceptions of snus, dissolvable tobacco products, and electronic cigarettes: Findings from a focus group study. American Journal of Public Health, 102, 2088-2093. https://doi.org/10.2105/ AJPH.2011.300525.

Cooper, M., Harrell, M. B., Pérez, A., et al. (2016). Flavorings and perceived harm and addictiveness of e-cigarettes among youth. Tobacco Regulatory Science, 2, 278-289. https://doi.org/10.18001/TRS.2.3.7.

Creamer, M. R., Loukas, A., Li, X., et al. (2016). College students' perceptions and knowledge of hookah use. Drug and Alcohol Dependence, 168, 191-195. https://doi. org/10.1016/j.drugalcdep.2016.09.004.

Dutra, L. M., \& Glantz, S. A. (2014). Electronic cigarettes and conventional cigarette use among US adolescents: A cross-sectional study. JAMA Pediatrics, 168(7), 684. https:// doi.org/10.1001/jamapediatrics.2013.5488.

Eissenberg, T., Ward, K. D., Smith-Simone, S., et al. (2008). Waterpipe tobacco smoking on a U.S. College campus: Prevalence and correlates. The Journal of Adolescent Health, 42, 526-529. https://doi.org/10.1016/j.jadohealth.2007.10.004.

Farrelly, M. C., Duke, J. C., Nonnemaker, J., et al. (2017). Association between the real cost media campaign and smoking initiation among youths - United States, 20142016. MMWR. Morbidity and Mortality Weekly Report, 66, 47-50. https://doi.org/10. 15585/mmwr.mm6602a2.
Grana, R., Benowitz, N., \& Glantz, S. A. (2014). E-Cigarettes: A scientific review. Circulation, 129, 1972-1986. https://doi.org/10.1161/CIRCULATIONAHA.114. 007667.

Halpern-Felsher, B. L., Biehl, M., Kropp, R. Y., et al. (2004). Perceived risks and benefits of smoking: Differences among adolescents with different smoking experiences and intentions. Preventive Medicine, 39, 559-567. https://doi.org/10.1016/j.ypmed.2004. 02.017 .

Hatsukami, D. K., Biener, L., Leischow, S. J., et al. (2012). Tobacco and nicotine product testing. Nicotine \& Tobacco Research, 14, 7-17. https://doi.org/10.1093/ntr/ntr027.

Hyland, A., Ambrose, B., Conway, K. P., et al. (2017). Design and methods of the Population Assessment OF Tobacco and Health study. Tobacco Control, 26(4), 371-378. https://doi.org/10.1136/tobaccocontrol-2016-052934.

Kaufman, A. R., Suls, J. M., \& Klein, W. M. (2016). Communicating tobacco product harm: Compared to what? Addictive Behaviors, 52, 123-125. https://doi.org/10.1016/j. addbeh.2015.06.039.

Lumley, T. (2015). Package survey: Analysis of complex survey samples. $R$ Package version 330.

Maziak, W., Eissenberg, T., \& Ward, K. D. (2005). Patterns of waterpipe use and dependence: Implications for intervention development. Pharmacology, Biochemistry, and Behavior, 80, 173-179. https://doi.org/10.1016/j.pbb.2004.10.026.

Maziak, W., Ward, K. D., \& Eissenberg, T. (2007). Interventions for waterpipe smoking cessation. Cochrane Database of Systematic Reviews, Cd005549. https://doi.org/10. 1002/14651858.CD005549.pub3.

Pearson, J. L., Richardson, A., Niaura, R. S., et al. (2012). E-cigarette awareness, use, and harm perceptions in US adults. American Journal of Public Health, 102, 1758-1766. https://doi.org/10.2105/AJPH.2011.300526.

Pepper, J. K., Ribisl, K. M., \& Brewer, N. T. (2016). Adolescents' interest in trying flavoured e-cigarettes. Tobacco Control. https://doi.org/10.1136/tobaccocontrol-2016053174.

Persoskie, A., O'Brien, E. K., Nguyen, A. B., et al. (2017). Measuring youth beliefs about the harms of e-cigarettes and smokeless tobacco compared to cigarettes. Addictive Behaviors, 70, 7-13. https://doi.org/10.1016/j.addbeh.2017.01.033.

Ramsay, J. O. (1991). Kernel smoothing approaches to nonparametric item characteristic curve estimation. Psychometrika, 56, 611-630.

Roditis, M., Delucchi, K., Cash, D., et al. (2016). Adolescents' Perceptions of health risks, social risks, and benefits differ across tobacco products. Journal of Adolescent Health, 58, 558-566. https://doi.org/10.1016/j.jadohealth.2016.01.012.

Sijtsma, K. (2009). On the use, the misuse, and the very limited usefulness of Cronbach's Alpha. Psychometrika, 74, 107-120. https://doi.org/10.1007/s11336-008-9101-0.

Sijtsma, K., \& Meijer, R. R. (2007). Nonparametric item response theory and related topics. Handbook of statistics. Vol. 26Elsevier B.V ISSN: 0169-7161.

Sijtsma, K., \& Molenaar, I. (1987). Reliability of test scores in nonparametric item response theory. Psychometrika, 52, 79-97.

Song, A. V., Morrell, H. E., Cornell, J. L., et al. (2009). Perceptions of smoking-related risks and benefits as predictors of adolescent smoking initiation. American Journal of Public Health, 99, 487-492. https://doi.org/10.2105/AJPH.2008.137679.

Strong, D. R., Hartman, S. J., Nodora, J., et al. (2015). Predictive validity of the expanded susceptibility to smoke index. Nicotine \& Tobacco Research, 17, 862-869. https://doi. org/10.1093/ntr/ntu254.

Team, R. C. (2016). R: A language and environment for statistical computing. $R$ foundation for statistical computing.

U.S. Department of Health and Human Services (2012). Preventing tobacco use among youth and young adults: a report of the surgeon general. U.S. department of health and human services centers for disease control and preventionAtlanta, Georgia: Office of Smoking and Healthhttps://www.ncbi.nlm.nih.gov/books/NBK99237/\#!po = 25 . 0000 .

U.S. Department of Health and Human Services (2014). The health consequences of smoking-50 years of progress: A report of the surgeon general. U.S. department of health and human services centers for disease control and preventionAtlanta, Georgia: Office of Smoking and Healthhttps://www.surgeongeneral.gov/library/reports/50years-of-progress/full-report.pdf.

United States Department of Health and Human Services. National institutes of health. National institute on drug abuse, and united states department of health and human services. Food and drug administration. Center for tobacco products. Population Assessment of tobacco and health (PATH) study [United States] Restricted-use files. ICPSR36231-v12. Ann arbor, MI: Inter-university consortium for political and social research [distributor], 2017-04-27. https://doi.org/10.3886/ICPSR36231.v12.

Wakefield, M., Morley, C., Horan, J. K., et al. (2002). The cigarette pack as image: New evidence from tobacco industry documents. Tobacco Control, 11(Suppl. 1), I73-I80.

Ward, K. D., Eissenberg, T., Gray, J. N., et al. (2007). Characteristics of U.S. waterpipe users: A preliminary report. Nicotine \& Tobacco Research, 9, 1339-1346. https://doi. org/10.1080/14622200701705019. 